\title{
A Review of Translucent Concrete as a New Innovative Material in Architecture
}

\author{
Dalia Elgheznawy*, Sara Eltarabily \\ Department of Architecture and Urban Planning, Faculty of Engineering, Port-Said University, Egypt
}

Received June 1, 2020; Revised July 13, 2020; Accepted July 29, 2020

Copyright $\bigcirc 2020$ by authors, all rights reserved. Authors agree that this article remains permanently open access under the terms of the Creative Commons Attribution License 4.0 International License

\begin{abstract}
Recently, the concept of green architecture has become a common interest in various disciplines; innovative materials are continuously developed to fulfill the green architecture requirements. Translucent concrete (TC) or light-transmitting concrete (LTC) is produced as one of those innovative types of materials which allows external light to transmit through interior spaces by using some light elements like optical fibers with concrete. This paper aggregates and reviews the previous studies in terms of translucent concrete' applications, proper ratio and arrangement pattern of optical fibers, light-transmitting, mechanical, thermal and energy-saving properties. We reviewed the remarkable studies carried out especially last 10 years in translucent concrete techniques. Notwithstanding the advantages, literature concurs that several gaps were found in translucent concrete studies. Translucent concrete' strength and proper ratio of fibers are key limitations. The gap between studies examining the effect of using different ratios of optical fibers on the material strength and on energy-saving concluded that the proper ratio of fibers should be less than $5 \%$ for strength, and the optimum ratio ranges $4.3 \%$ to $6 \%$ for energy-saving. We identify possible areas for future research and suggest recommendations in the conclusion to fill these gaps.
\end{abstract}

Keywords Translucent Concrete, Light-transmitting Concrete, Material, Energy-saving

\section{Introduction}

Concrete can be considered as one of the significant building materials used worldwide. Translucent concrete is considered as a type of fiber-enhanced concrete. The first translucent concrete concept was presented in 2001 by Aron Losonczi, and in 2003 the first block of translucent concrete was successfully manufactured which known as
"LiTraCon" [1]. Utilizing translucent concrete material as a building envelope in addition to being an aesthetic element $[2,3]$, it allows the light to enter the interior spaces, reducing the need for lighting. A study made by Bhushan, et al. 2013 [4]; clarified the definition with the light-transmitting property because of the use of light optical elements, and reviewed the advantages and disadvantages of translucent concrete blocks. They concluded that there were many ways to use translucent concrete and actualized it into numerous shapes to be profoundly advantageous. Although the basic idea of translucent concrete was to apply it in architecture as a façade material [7], there are few researches in this field. Be that as it may, the most prominent disadvantage can be considered high construction costs. Few studies have examined the cost of producing translucent concrete. Other studies have tended to add new materials to the concrete to achieve light transmission. Also, a new type of translucent concrete panel by mixing preformed resin with the concrete was developed [5].

Translucent concrete almost consists of the same main components of traditional concrete such as cement, water, sand, and without coarse aggregates, besides, the specific amount of light transmitting elements as plastic fiber, and glass fiber. There are several ways to produce it, but the most popular trademark for translucent concrete material is "LiTraCon" which is made of $96 \%$ concrete and $4 \%$ by weight of optical fibers [6].

According to the Web of Science core collection database and Scopus database, most of previously published studies especially the last 10 years in the translucent concrete technique indicate a growing interest in this field. Focusing on studies done in the field of translucent concrete applications; these have not only discussed the aesthetic purposes for translucent concrete $[8,9]$, but translucent concrete has also been tested as a light-transmitting material that affects energy consumption by decreasing the demand of the illumination [10-12]. In addition, some studies focused on testing the thermal 
properties that affect the calculations of the heating and cooling loads on the Heating, ventilation, and air conditioning (HVAC) system [33-38]. With the growing interest of researchers to investigate translucent concrete' functional properties; most of previous studies tested the effectiveness of mechanical properties by using varied patterns and ratios of optical fibers, and by comparing the compressive strength of translucent concrete with the conventional concrete [19-32].

This paper aims to review the remarkable studies carried out in the field of translucent concrete' applications, material properties, thermal and energy-saving, and light-transmitting. Because there aren't any of reviewed studies that achieve both maximum energy-saving and better mechanical properties, so the paper discusses the gap in differing of the ratios of optical fibers in translucent concrete between researches interested in studying translucent concrete' compressive strength and ones interested in studying energy saving.

\section{Applications of Translucent Concrete in Different Fields}

Until now, translucent concrete is manufactured as precast blocks and wall panels. Therefore, the use of translucent concrete has not yet been widely applied. Next, are some of their applications:

Aesthetic purpose: One of the most important applications of translucent concrete is to use it in facades as an aesthetic element in buildings [8]. They can, therefore, be used in museums, galleries and also in art or design projects used as decorative materials instead of just building materials [9].

Illumination buildings interiors: The main use of translucent concrete is to illuminate the interior spaces, as it is mentioned in a previous study [10], according to the ability of translucent concrete to transmit light to interior spaces such as educational buildings. Translucent concrete is used widely in exterior facades, partition walls, and floors. But there are few or no researches in the acoustic isolation properties.

Staircases and inner walls: When applying translucent concrete on the outer wall of an indoor stairwell, it allows the sunlight to enter the interior space, and thus can be a good solution during the evacuation of buildings in emergencies and power outages, especially in skyscraper buildings [1].

Energy-saving: Some recent researches study the application of the use of translucent concrete panels in facades or ceilings of any large building which helps reduce lighting costs, to fulfil the environment and green architecture requirements, where translucent concrete can be used as a means to reduce energy consumption by decreasing the demand of the illumination [11]. Translucent concrete can be considered a green energy-saving construction material, where a special sort of translucent concrete is manufactured to study properties as a material to save energy. The possibility of using waste glass with optical fibers in translucent concrete to be more environmentally friendly buildings was studied [12].

Doors and front walls: Dealt with one of the suggestions regarding the application of translucent concrete is to use it in the exterior doors of houses so that residents can know the presence of people outside [13].

Translucent concrete as a material: According to several studies, one of the applications of the use of translucent concrete is to use it as a lightweight material that reduces the dead load on the structural structure of buildings. A previous study demonstrated the effectiveness of the use of translucent concrete through its ability to transmit light with an impact on manufacturing cost [14]. Another study about using different percentages of optical fibers mixed with concrete compared to conventional concrete, several tests were carried out such as compressive strength tests. The results showed the ability of translucent concrete to transmit light almost without affecting the strength of concrete [15].

Some recent researches are moving towards studying to mix new materials into translucent concrete panels to try to reduce the weight of concrete, enhance their strength and produce them as an environmentally friendly material.

Sidewalks, Speed bumps, and Roads lane markers: translucent concrete material can be used to light the in sidewalks at night for public safety, and increasing visibility in dark subway stations, in addition to the possibility of use in lighting industrial bumps. A detailed study on the application of the use of translucent concrete in the road lane markers for road lighting was presented [16].

Road tunnels and subway stations: translucent concrete is applied to lighting road tunnels or Subway stations. A scale model of a tunnel road based on the use of translucent concrete in the gaps between the beams to introduce sunlight to try to develop, and study the use of translucent concrete in road tunnels, was simulated [17]. But it is expensive for road tunnels purposes [18].

Through the applications that are listed above, it seems that scientific research in the field of applications of the use of translucent concrete needs more studies to take advantage of its thermal performance and light transmission.

\section{Effectiveness of Translucent Concrete' Mechanical Properties}

Translucent concrete is considered a new material in the construction sector, and with the growing interest of current researchers to investigate its functional properties; It was necessary to test the mechanical properties by comparing the compressive strength of translucent 
concrete with the conventional concrete especially taking into consideration the importance of results at 28 days for research work more than 7 days results. Because of using optical fibers as the distinctive component of translucent concrete which is embedded in concrete blocks; it is important to review the literature that addressed:

- The effect of using various light transmitting elements like optical fibers within the concrete mixture.

- The proper volume ratio of optical fibers.

- The different arrangement patterns of fiber strands on the strength property of concrete.

\subsection{Effect of Using Light Transmitting Elements Within the Concrete Mixture}

The principle of using translucent concrete in modern construction as a green architectural material is based on Nano-optics like optical fibers or large diameter glass fiber. Some researchers have generally assumed that the use of optical fibers in a traditional concrete mixture to produce translucent concrete that may have nearly the same compressive strength property as conventional concrete, therefore, it may not weaken the effect on structural purposes. On the other hand, it supports the aesthetical, and energy-saving [19].

A study for developing decorative purposes and the strength properties of the light-transmitting concrete were experimentally investigated [20]. The main purpose is to use optical fibers that arranged in different layers in the formwork before casting cubes to determine the concrete compressive strength during four weeks. This study tested (0.45) mix ratio of optical glass fiber that randomly distributed in a concrete cube of $150 \mathrm{~mm}$ size, and recorded about $25 \mathrm{~N} / \mathrm{mm}^{2}$ compressive strength for after 28 days using compression testing machine (CTM), they concluded that the light-transmitting concrete could be considered structural efficient like decorative when compared to conventional concrete.

Other studies tested different fiber volume ratios on the compressive strength of translucent concrete [8]. The effect of optical fibers that used instead of metal wires in concrete to increase its strength and durability was investigated. This experimental work was designed for light-transmitting concrete of the grade of concrete mix with the compressive strength, with different diameters of optical fibers from 0.25 to $3 \mathrm{~mm}$ with mix ratio (0.4). They concluded that using optical fibers-based concrete can improve the concrete structural efficiency when compared to normal concrete by increasing the compressive strength, and by reducing the tensile and flexural strength.

Referring to the effect of optical fibers arrangement pattern [21]; An experimental work was designed for light-transmitting concrete with three different patterns of arrangement of optical fibers to test the strength properties of light-transmitting concrete based on cracking state that happened. And hence the results showed the significant effect of optical fibers quantity and its arrangement on the compressive strength, especially in case of using concentric circle pattern. So, this requires optimizing the plastic optical fibers arrangement in the panels.

\subsection{Proper Ratio and Arrangement Pattern of Optical Fibers}

The optical fibers volume ratio of concrete is proportionate to transmission light property. And because the procedure of manufacturing transmitting concrete is to use optical fibers with cement in the mortar, this may improve the light transmit property. But about the exact effect of optical fibers ratio on the characteristics of transmitting concrete, it needs to evaluate the properties of concrete panels in terms of proper ratio and arrangement pattern of optical fibers [22].

Also, the effectiveness of translucent concrete regarding light transmits property and transmission ability of the optical fibers was evaluated [23]. In terms of the optical fibers volume ratio to the concrete mixture, they concluded that the volume ratio is proportional to light transmission, besides it affects the compressive strength of the concrete.

The effect of plastic optical fibers on the properties of transmitting concrete was studied [24]. The results due to compressive strength increased with the increase of plastic optical fibers ratio which was experimentally investigated by compression testing machine (CTM) when using six ratios $(0 \%, 0.06 \%, 0.12 \%, 0.36 \%, 1.43 \%$, and $1.59 \%)$. The greatest value was recorded with plastic optical fibers of $1.43 \%$ and $1.5 \mathrm{~mm}$ diameter at 28 days test. Another study tested $(1 \%)$ volume ratio for plastic optical fibers with 1 $\mathrm{mm}$ diameter strands for a cube of $70 \mathrm{~mm}$ size as shown in Figure 1(a) that resulted in a high value of compressive strength $36.7 \mathrm{~N} / \mathrm{mm}^{2}$ by using compression testing machine (CTM) [25].

Toward developing the characteristics of transmitting concrete, its usage and advantages were discussed [26]. The light-transmitting, compression, and the properties of plastic optical fibers based concrete block were experimentally investigated using varied ratios $(3.14 \%$, $3.80 \%, 4.52 \%$, and $5.3 \%$ ) [1]. They provided solid evidence for the effect of the internal plastic optical fibers area ratio on the concrete blocks' light transmit performance, especially when the proportion ratio of the optical fibers was less than $5 \%$. Additionally, it can be considered as a green building material that provides the energy-saving and a steady light-transmitting ratio.

A recent study experimentally tested the compressive strength of translucent concrete side by side with the light-transmitting property [27], they cast concrete cube of $100 \mathrm{~mm}$ size with different volume ratios of plastic optical fibers varied from 0.25 to $4 \%$ with $0.5 \mathrm{~mm}$ diameter. Results showed an increase in compressive strength by compression testing machine (CTM) when using plastic 
optical fibers ratios from $0.25 \%$ to $2 \%$, but by an increase, this ratio up to $4 \%$, about $15 \%$ reduction in compressive strength was obtained from $26 \mathrm{~N} / \mathrm{mm}^{2}$ to $22 \mathrm{~N} / \mathrm{mm}^{2}$. From these previous results, we may consider the optimum ratio should be about $3 \%$ of optical fibers.

The compressive strength of translucent concrete was experimentally investigated [28], and they discussed the effect of four different diameters $(1.5,2,2.5$, and $3 \mathrm{~mm})$ and three different ratios $(2 \%, 4 \%, 6 \%)$ of plastic optical fibers in concrete cubes. They concluded at 7 days that compressive strength is gradually increased by increasing ratio to $4 \%$. But when the plastic optical fibers ratio was increased up to $6 \%$, the compressive strength was contrarily relative to the proportion. On the other hand, results at 28 days showed directly proportional relation between compressive strength and fiber diameter and recorded $3 \mathrm{~mm}$ diameter with a fiber content of $4 \%$ as a good result.

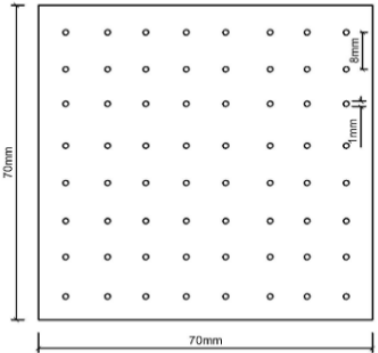

(a)

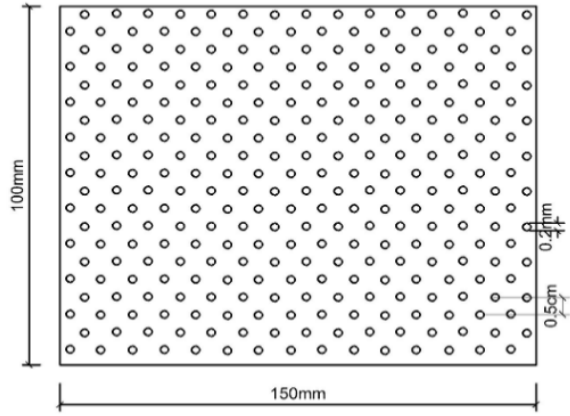

(b)

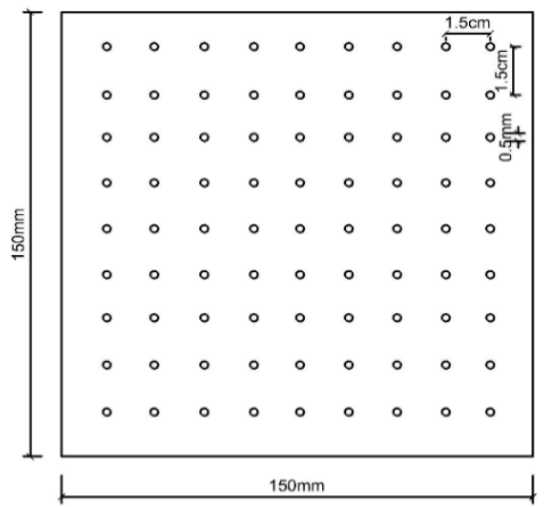

(c)

Figure 1. fibers specimen's perforated boards: (a) cube of 70mm size; (b) cuboid 150mm*100mm*100mm; (c) cube of 150mm size, adapted from (S. Luhar et al. 2015, A.Momin et al. 2014)

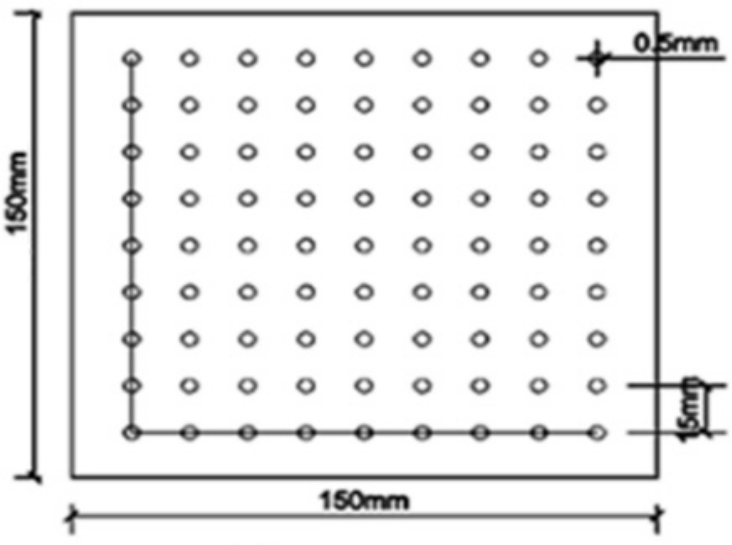

(a)

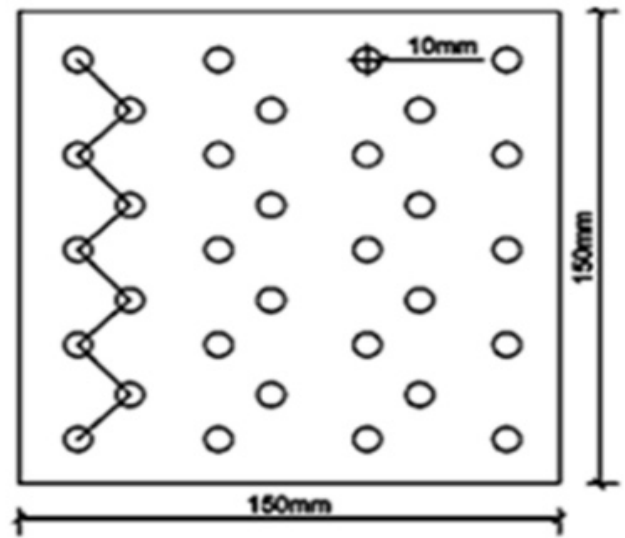

(c)

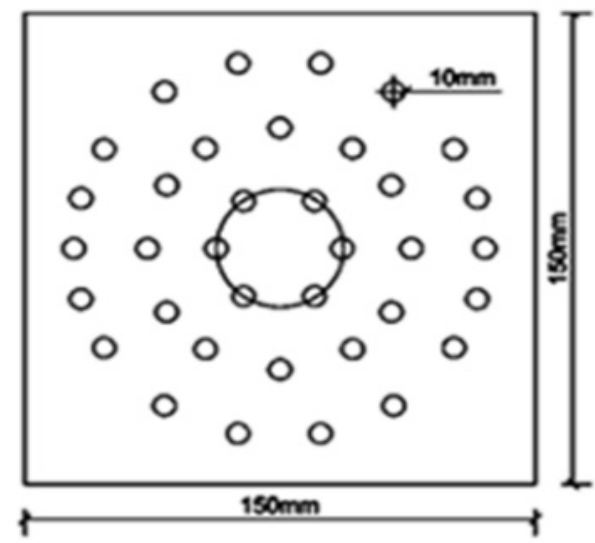

(b)

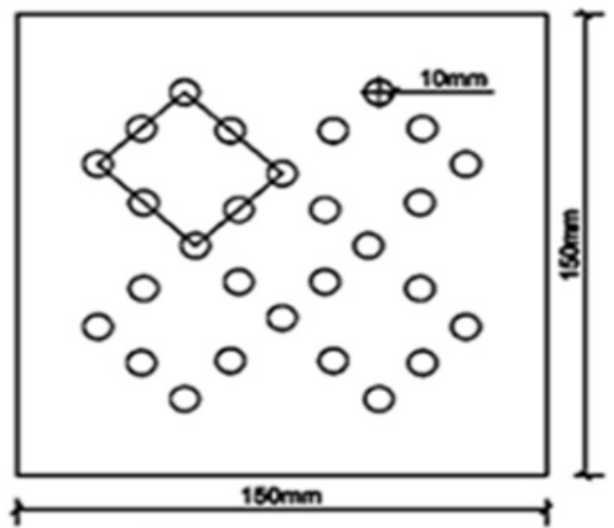

(d)

Figure 2. The arrangement pattern of fibers: (a) grid; (b) concentric; (c) zigzag; (d) cluster, adapted from (K, R, and D 2019, A.Momin et al. 2014) 
A cuboid as shown in Figure 1(b) was experimentally investigated in three different spacing of optical fibers strands $(0.5,1$, and $2 \mathrm{~cm})$ with $0.2 \mathrm{~mm}$ diameter strands [29]; the best result in terms of strength property of concrete was $23 \mathrm{~N} / \mathrm{mm}^{2}$ for using $0.5 \mathrm{~cm}$ spacing. And also, they experimentally investigated a cube of $150 \mathrm{~mm}$ size in three different spacing of glass rods $(1.5,3$, and $4.5 \mathrm{~cm})$ with $0.5 \mathrm{~mm}$ diameter Rods as shown in Figure 1(c), the best result in terms of strength property of concrete was 26 $\mathrm{N} / \mathrm{mm}^{2}$ for using $4.5 \mathrm{~cm}$ spacing. Finally, by comparing their specifications with the normal concrete in term of the strength property of translucent concrete, the results for 4.5 $\mathrm{cm}$ spacing of glass rods was greater than the normal concrete.

A recent study focused on testing various arrangement pattern of plastic optical fibers instead of the grid pattern [21] as shown in Figure 2; it investigated area ratio of fibers to the area of concrete by replacing $15 \%$ of concrete area by patterns of $10 \mathrm{~mm}$ diameter holes and also investigated three patterns of fiber alignment in the concrete specimens (Zig-zag pattern, Concentric circle pattern, and Cluster pattern) by casting cube of $150 \mathrm{~mm}$ size. Based on the crack pattern, the concentric circle pattern of the arrangement of optical fibers produced good results in the compressive strength of translucent concrete.

\subsection{Alternatives of Using Light Transmitting Elements Instead of Optical Fiber}

About how Light-transmitting concrete made; the difficulty of being poured on-site like traditional concrete, and the inevitable of being produced as precast or prefabricated blocks and panels, was explained [30]. The study indicated that Light-transmitting concrete can be produced by adding volume ratio $4 \%$ to $5 \%$ of fiber filaments lay parallel to each other into the concrete mixture, or by using woven fiber fabric instead of fiber strands at intervals of approximately ( $2 \mathrm{~mm}$ to $5 \mathrm{~mm}$ ); to test compressive strength, light transmission, and to coordinated the principle of green energy-saving with the utilization of the properties of the translucent concrete as a new kind of functional building material.

To investigate adding recycled materials to translucent concrete instead of optical fibers; glass with ratio $(0 \%, 5 \%$, $10 \%$, and $30 \%$ ) into concrete was used [12], and it was obtained that the compressive strength at 28 days was gradually reduced $34.2 \mathrm{~N} / \mathrm{mm}^{2}$ to $26.9 \mathrm{~N} / \mathrm{mm}^{2}$. The effect of adding another glass rods ratios of $(1 \%, 2 \%, 3 \% 4 \%$ $5 \%$ at $1.5 \mathrm{~cm}$ spacing on compressive strength was tested [31], the results were slightly positive $26.4 \mathrm{~N} / \mathrm{mm}^{2}$ due to measuring compressive strength at 28 days to a glass rod ratio of up to $3 \%$, and then the decrease in compressive strength occurred.

The effect of using different materials like glass rods with three different percentages used in producing translucent concrete specimens was discussed [29].
Experimental tests were executed comparing its specifications with the traditional concrete. In term of the compressive strength test of translucent concrete, the results acquired for the specimens with glass rods was more than the normal concrete specimens between 24 $\mathrm{N} / \mathrm{mm}^{2}$ and $26 \mathrm{~N} / \mathrm{mm}^{2}$, which indicated that the translucent concrete fulfilled the compressive strength necessities.

As for the use of different thickness translucent concrete boards $(15,25$, and $50 \mathrm{~mm})$, with $4 \%$ plastic optical fibers volume and (2, and $3 \mathrm{~mm})$ diameter were produced [32]. They tested the mechanical effects like Flexural strength, density, and toughness. The experimental results regarding density were inversely proportional to the minimum thickness as a lightweight material, and regarding flexural strength, the boards contain plastic optical fibers with a $2.0 \mathrm{~mm}$ in diameter have the highest value.

Finally, all previous researches have been measuring, comparing the strength property of translucent concrete with traditional concrete, and trying to enhance strength and durability of this concrete as a structural material by adding various types of light transmitting elements with different ratios, although these existing studies have given acceptable overall values in term of compressive strength.

\section{Translucent Concrete' Light Transmitting Property}

Few previous studies that have discussed the light-transmitting property of translucent concrete, regarding that, it was directly proportional to the increase of optical fibers ratios and diameter. A previous study simulated and experimentally investigated in sample prototypes of concrete panels [33]. The impact of using coarse waste glass scraps coming from the glass industry was analyzed in terms of light transmittance performances (LT) and energy demand for lighting. The experimental results showed good potentials concerned with the use of concrete panels with a light transmittance of $5 \%$ as a function of the glass's volume. As a consequence, the reduction range in energy demand for lighting was calculated in simulations from $12.7 \%$ to $16 \%$ with light transmittance 5\%. Even better application of studied concrete panels is for internal walls instead of for envelope components.

In terms of the importance of determining the volume ratio of the fibers in translucent concrete panels and its effect on daylight transmission properties; the transmitted luminous flux by using (2, and $3 \mathrm{~mm}$ ) optical fibers with different volume ratios were experimentally tested [2]. The best results were shown using $3 \mathrm{~mm}$ diameter with about $5 \%$ volume ratio in the specimen ( 7 in.*7 in. $* 0.5$ in.) Light transmission simulation of straight optical fibers showed light loss due to bending of the fiber, although this is not available during the actual process of construction, the 
results recommended that bending radius should be less than 15 times fiber diameter as it affects the light transmission performance. Also, the study tested another different translucent concrete panels of the varied thickness $(3,6$, and $10 \mathrm{~mm})$ that was designed as a replacement for windows to measure the light transmission from outside to inside, illuminance results confirmed that the distribution and spaces between fibers were vital factors affects daylight entered a space.

Light transmitting ability for six specimens with different plastic optical fibers diameter, volume ratio, and spacing was experimentally studied [24]. Logically, light-transmitting increased with the percentage of plastic optical fibers, but without affecting compressive strength. In term the fibers can enhance the strength and appearance, the best result of illuminance was by using $1.43 \%$ of fibers that were $1.5 \mathrm{~mm}$ diameter distributed every $10 \mathrm{~mm}$.

\section{Thermal and Energy-saving Properties of Translucent Concrete}

Translucent concrete considered a green material, can reduce energy consumption by reducing the demand for the electricity used for artificial lighting during the day as well as reducing the demand for heating loads in the winter, although it can increase cooling loads [34]. The presented research summarizes the previous studies on thermal and lighting analyses researches of translucent concrete that would result in energy-saving

An experimental study on a translucent concrete panel investigated the light emissions and thermal properties by modelling the arrangement of the optical fibers into the concrete during exposure to simulated sunlight for 12 months. Results proved the good thermal and mechanical properties of translucent concrete [23].

Computational modelling for a translucent concrete panel with dimensions $(0.3 \mathrm{~m} * 0.3 \mathrm{~m} * 0.1 \mathrm{~m})$ was designed [35], to study light transmission properties in the model with the weather conditions of Berkeley, California using a fiber volumetric ratio of $10.56 \%$. Over a year simulation, an algorithm is applied to simulate and calculate- as a computational- model the solar heat absorption of the translucent concrete panel. The results of this study are to set a method for calculating the amount of sun entering the building applying translucent concrete. This will influence future design decisions during the Heating, ventilation, and air conditioning (HVAC) design process.

Complementing the previous paper, new research was done to present thermal and lighting analysis [36], and to find the best ratio of optical fibers for translucent concrete panels that will achieve maximum energy-saving. The study depends on manufacturing panels in the laboratory with the same dimensions of the computational model in previous reteach, applied to a model room with dimensions $(3 \quad \mathrm{~m} * 3 \quad \mathrm{~m} * 2.895 \mathrm{~m})$. A software was developed to do the simulations and the calculations of the heating and cooling loads on the Heating, ventilation, and air conditioning (HVAC) system, and other light and thermal analysis to calculate the best ratio of optical fibers for panels that will achieve maximum energy-saving. This finds that using a fiber volumetric ratio of about $6 \%$ reduces energy consumption by $18 \%$.

A recent study was elaborated on the creation of an experimental apparatus for conducting thermal conductivity and transmittance tests in a translucent concrete block whose fiber percentage is $4.1 \%$ [37], and comparing with the one without fibers, since few researches have studied these properties. This study found that translucent concrete conducts less heat than non-fiber concrete, since the thermal conductivity coefficient, whose bulk density is between $2200 \mathrm{Kg} / \mathrm{m}^{3}$ and 2400 $\mathrm{Kg} / \mathrm{m}^{3}$, is equal to $1.75 \mathrm{~W} /(\mathrm{mk})$, and through the tests it was found that the translucent concrete is $1.61 \mathrm{~W} /(\mathrm{mk})$, showing that the addition of optical fibers in the concrete makes it a better thermal insulator.

A new translucent concrete panel with $(50 \mathrm{~cm} * 50$ $\mathrm{cm} * 2.5 \mathrm{~cm}$ ) dimensions was tested [33] through combining with coarse flat glass scraps, a high resistance self-compacting mortar with coarse waste glass. The study carried out both an experimental study and simulations to study the light transmittance and its impact on energy demand for lighting. Based on his calculations the energy demand for lighting decreases as the Light transmittance value of the translucent concrete panels increases: this decrease was in the range 6 to $20 \%$.

Also, the light transmittance properties, mechanical properties, and thermal performance of a new sort of resin translucent mortar-based concrete were experimentally and numerically investigated [38]. Their observations indicated $60 \%$ low of the translucent concrete thermal conductivity $0.3815 \mathrm{~W} /(\mathrm{mk})$ than the traditional concrete $0.89 \mathrm{~W} /(\mathrm{mk})$.

A recent study was made to simulate the effect of different factors on the passage of light through transparent concrete [39] and to simulate the size of fibers in the study to reach the optimum ratio of lighting during the use of transparent concrete. Few researches have been measuring these properties or comparing thermal performance and light-transmitting of translucent concrete with traditional concrete, although these existing studies have been given a positive overall indicator in terms of energy demand.

Summarizing the above; Through previous studies presented in this paper, there is a gap in researches linking the best ratios of the optical fibers in concrete to achieve both maximum energy-saving and better mechanical properties, as shown in Figure 3. 


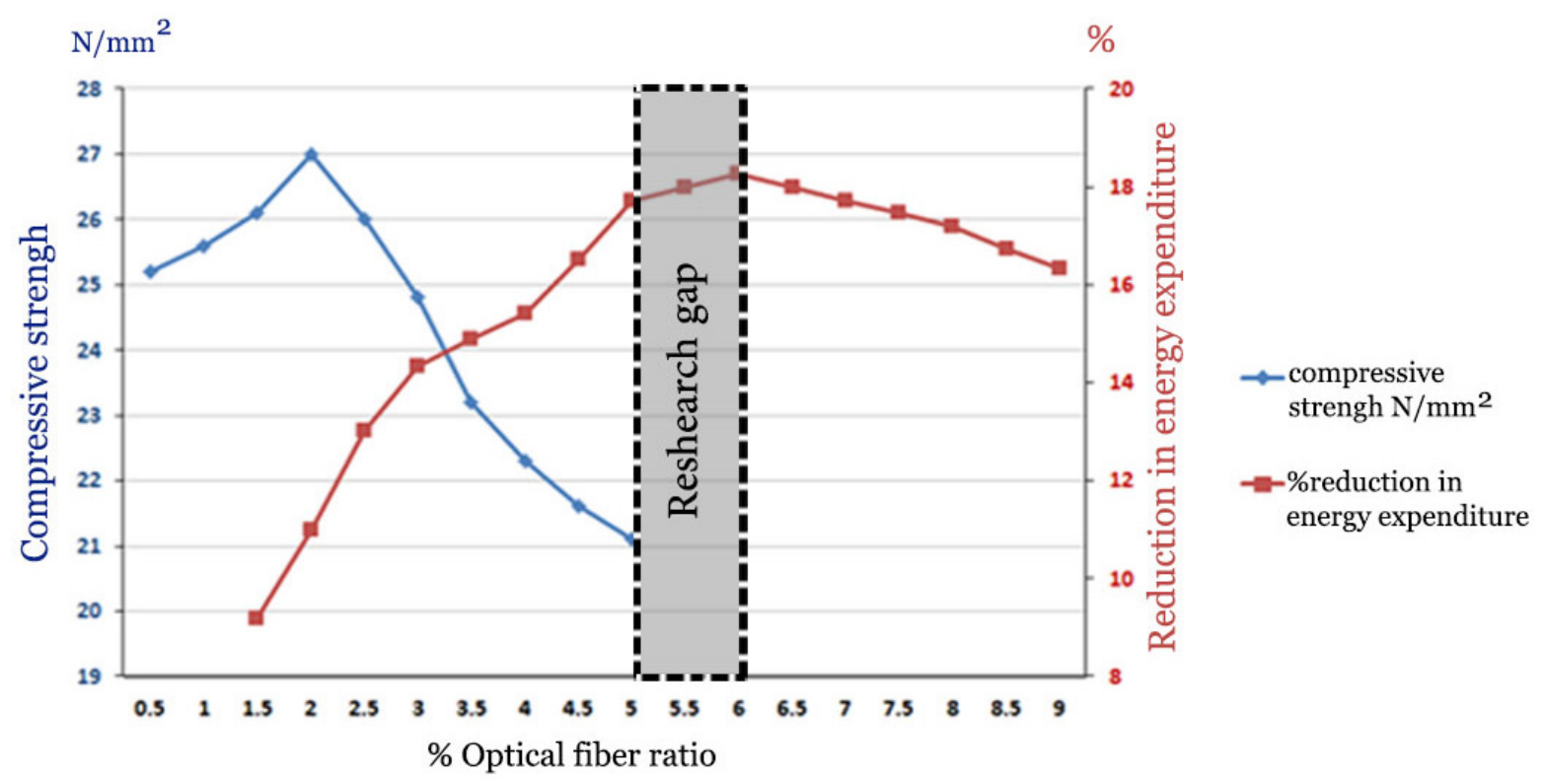

Figure 3. The gap in the study of the rates of use of optical fibers between researches interested in the study of translucent concrete compressive strength and researches interested in the study energy saving, Adapted from ( A. Ahuja and K. M. Mosalam, 2017), and the previous studies presented in this paper

\section{Conclusions}

This paper presented the results and conclusions of translucent concrete previous researches to be used as a guide to develop further studies about this field, and the following conclusions are based on the observations of these previous research.

Translucent concrete has many applications not only for aesthetic purposes but also used as illumination building interiors and structural lightweight material, and this needs further studies to expand its uses. As it is motioned in this paper earlier, translucent concrete can insert the light inside the spaces and can, therefore, be applied in educational buildings instead of windows. Also, it is necessary to have researches in the field of acoustic isolation of translucent concrete where there are few or no researches on this field, which is important to expand the scope of applications of translucent concrete.

Most researches in the field of thermal and energy-saving tend to experimental or simulation studies of the feasibility of adding optical fibers with the concrete to insert sunlight into the interior spaces and investigated in their ratios in concrete. Aims to reach the best ratios to achieve the optimum energy-saving by reducing the demand for industrial lighting and heating loads in winter. Where the average of results from the previous studies indicated that $6 \%$ and up of the fibers in concrete volume is the perfect ratio for energy-saving which was between $12.7 \%$ and up to $18 \%$.

Concerning mechanical properties of translucent concrete, there are numbers of researches compared to properties of translucent concrete with conventional one, especially recording the compressive strength value as one of the most significant properties of concrete material. However, most researches have shown that the mechanical properties of the strength of translucent concrete are still less than that of ordinary concrete and need more investigations.

On the other hand, some researches investigated the effect of adding fibers in translucent concrete on the mechanical properties regarding the fibers' ratios. A lot of these studies experimentally investigated the effect of optical fibers ratio into the concrete mixture that varied from $0 \%$ to $6 \%$ with different diameters, to improve the strength performance. As expected, the results proved that compressive strength decreased by increasing the ratio of the optical fibers and indicated that less than $5 \%$ of the fibers in concrete volume is the perfect ratio for mechanical properties.

There are few researches on the arrangement pattern of fibers into concrete specimens that is considered a good indicator affects compressive strength property depending on cracks pattern. And this point needs to be widely investigated in future researches. As for an effective factor in very few researches, adding an alternative component to the concrete mixture like plastic optical fibers, glass rods instead of optical fibers is to reinforce the mechanical properties of translucent concrete and aims to increase the strength and light-transmitting properties together. But, more researches into the test of new materials to support translucent concrete are still needed.

As mentioned before, the proper ratio of fibers in concrete volume for energy-saving is $6 \%$ and up and is less than $5 \%$ for better mechanical properties. So, there is a gap in researches linking the best ratios of the optical fibers in concrete to achieve both maximum 
energy-saving and better mechanical properties within the range from $5 \%$ to $6 \%$. So, further studies are needed to develop the properties of translucent concrete regarding investigating adding alternative light-transmitting elements.

\section{REFERENCES}

[1] Z. Zhou, G. Ou, Y. Hang, G. Chen, and J. Ou, Research and development of plastic optical fiber based smart transparent concrete, presented at the Smart Sensor Phenomena, Technology, Networks, and Systems 2009, 2009. doi: $10.1117 / 12.816638$.

[2] K. M. Mosalam, N. Casquero-Modrego, J. Armengou, A. Ahuja, T. I. Zohdi, and B. Huang, Anidolic day-light concentrator in structural building envelope, in Proc., 1st Annual Int. Conf. on Architecture and Civil Engineering, 2013: Global Science and Technology Forum (GSTF) Singapore.

[3] K. Mosalam and N. Casquero-Modrego, Sunlight permeability of translucent concrete panels as a building envelope, Journal of Architectural Engineering, vol. 24, no. 3, p. 04018015, 2018. doi:10.1061/61/(ASCE)AE.1943-556 8.0000321 .

[4] M. N. V. P. Bhushan, D. Johnson, M. A. B. Pasha, and M. K. Prasanthi, Optical fibers in the modeling of translucent concrete blocks, International Journal of Engineering Research and Applications (IJERA), vol. 3, no. 3, pp. 013-017, 2013. doi: 10.9790/9622.

[5] A. G. Mainini, T. Poli, M. Zinzi, and S. Cangiano, Spectral light transmission measure and radiance model validation of an innovative transparent concrete panel for façades, Energy Procedia, vol. 30, pp. 1184-1194, 2012. doi: 10.1016/j.egypro.2012.11.131.

[6] B. Han, L. Zhang, and J. Ou, Smart and Multifunctional Concrete Toward Sustainable Infrastructures. Springer Singapore, 2017, pp. XXV, 400.

[7] A. Ahuja, K. M. Mosalam, and T. I. Zohdi, An illumination model for translucent concrete using radiance, in 14th International Conference of the International Building Performance Simulation Association (IBPSA), Hyderabad, India, 2015, pp. 2586-2579.

[8] R. Praveenkumar, S. Goumathy, K. M. Nomitha, A. R. A, and S. Mathew, An Experimental Study on Smart Transparent Concrete, International Journal of Innovative Research in Science, Engineering and Technology, vol. 6, no. 3, 2017. doi: 10.15680/IJIRSET.2017.0603158.

[9] A. Dhonchak, A Glowing Future - Transparent Concrete, International Journal Of Advance Research And Innovative Ideas In Education, vol. 2, no. 5, pp. 1465-1470, 2016. doi: 16.0415/IJARIIE-6254.

[10] A. Yadav, S. Shekhar, A. Anand, A. Badal, and B. Zaman, An investigating study on a new innovative material: transparent concrete, International Journal of Engineering Research and Advanced Development, vol. 4, no. 1, 2018. doi: $10.25215 / 23955163$.
[11] S. Paul and A. Dutta, Translucent concrete, International Journal of Scientific and Research Publications, vol. 3, no. 10, pp. 1-10, 2013. doi: 10.29322 .

[12] E. Jiménez-Muñoz and F. Fernández-Martínez, Translucent Concrete. Research with Glass, Optical Fiber and Glass Fiber, presented at the Construction and Building Research, Llinares-Millán 2014.

[13] R. Bajpai, Application of Transparent Concrete in Construction World, i-Manager's Journal on Civil Engineering, vol. 4, no. 1, p. 6, 2013. doi: 10.26634/jce

[14] U. M. Bhanuse, A. B. Babar, and A. C. Ranveer, Smart light translucent concrete by using optical fiber, Journal of Environmental Science, Computer Science and Engineering \& Technology, vol. 5, no. 1, pp. 10-18, 2015. doi: 10.24214/jecet.a.6.2.

[15] A. Sawant, R. Jugdar, and S. Sawant, Light transmitting concrete by using optical fiber, International Journal of Inventive Engineering and Sciences (IJIES), vol. 3, no. 1, pp. 23-28, 2014. doi: 10.35940/ijies.

[16] M. Saleem, M. M. Elshami, and M. Najjar, Development, Testing, and Implementation Strategy of a Translucent Concrete-Based Smart Lane Separator for Increased Traffic Safety, Journal of Construction Engineering and Management, vol. 143, no. 5, p. 04016129, 2016. Retrieved from https://ascelibrary.org/journal/jcemd4.

[17] A. Peña-García, L. M. Gil-Martín, and O. Rabaza, Application of Translucent Concrete for Lighting Purposes in Civil Infrastructures and its optical characterization, in Key Engineering Materials, 2016, vol. 663, pp. 148-156: Trans Tech Publ.

[18] A. Peña-García, R. Escribano, L. Gil-Martín, and A. Espín-Estrella, Computational optimization of semi-transparent tension structures for the use of solar light in road tunnels, Tunnelling and Underground Space Technology, vol. 32, pp. 127-131, 2012. doi: 10.1016/j.tust.2012.06.004.

[19] G. A. Covaleov, Translucent Concrete, in IOP Conference Series: Earth and Environmental Science, 2019, vol. 362, no. 1, p. 012144: IOP Publishing. doi:10.1088/1755-1315/362/ $1 / 012144$.

[20] P. M. Shanmugavadivu, V. Scinduja, T. Sarathivelan, and C. V. Shudesamithronn, An experimental study on light transmitting concrete, International Journal of Research in Engineering and Technology, vol. 3, no. 11, pp. 160-163, 2014. doi: $10.15623 /$ ijret.

[21] D. B. K, M. S. R, and S. D, Effect of Fiber Pattern in Strength of Light Transmitting Concrete, International Journal of Recent Technology and Engineering (IJRTE), vol. 7, no. 5S4, 2019. Blue Eyes Intelligence Engineering \& Sciences Publication. doi: 10.35940/ijrte.2277-3878

[22] N. Ravikumar and S. Dharsika, Experimental Study on Light Transparency of Concrete by Using Optical Fiber, International Journal of Scientific Engineering and Science, vol. 2, no. 2, pp. 1-4, 2018. Retrieved from http://ijses.com/volume-2-issue-2

[23] J. He, Z. Zhou, J. Ou, and M. Huang, Study on smart transparent concrete product and its performances, in The 6th International Workshop on Advanced Smart Materials and Smart Structures Technology, 2011, vol. 7, pp. 25-26. 
[24] A. Altlomate, F. Alatshan, F. Mashiri, and M. Jadan, Experimental study of light-transmitting concrete International Journal of Sustainable Building Technology and Urban Development, vol. 7, no. 3-4, pp. 133-139, 2016. doi: 10.1080/2093761X.2016.1237396.

[25] S. Luhar and U. Khandelwal, Compressive strength of translucent concrete, International Journal of Engineering Sciences \& Emerging Technologies IJESET, vol. 8, no. 2, pp. 52-54, 2015. doi: 10.7323/ijeset

[26] S. Juan and Z. Zhi, Some progress on smart transparent concrete, Pacific Science Review, vol. 15, no. 1, pp. 51-55, 2013. Retrieved fromhttps://www.sciencedirect.com/journa 1/pacific-science-review

[27] A. Kumar and R. Ahlawat, Experimental Study on Light Transmitting Concrete, IJISET - International Journal of Innovative Science, Engineering \& Technology, vol. 4, no. 6, 2017. doi: 10.13140/RG.2.2.22833.28008

[28] B. F. Bashbash, R. M. Hajrus, D. F. Wafi, and M. Alqedra, Basics of light transmitting concrete, Global Advanced Research Journal of Engineering, Technology and Innovation, vol. 2, no. 3, pp. 076-083, 2013. Retrieved from http://garj.org/garjeti

[29] A. Momin, R. Kadiranaikar, V. Jagirdar, and A. Inamdar, Study on light transmittance of concrete using optical fibers and glass rods, in International Conference on Advances in Engineering \& Technology, 2014, pp. 67-72.

[30] A. B. Kamdi, Transparent concrete as a green material for building, International Journal of Structural and Civil Engineering Research, vol. 2, no. 3, pp. 172-175, 2013. doi: $10.18178 /$ ijscer

[31] S. K., Transparent Concrete, International Journal of Engineering Technology Science and Research IJETSR, vol. 5 , no. 3, 2018. Retrieved from www.ijetsr.com
[32] S. A. Salih, A. P. D. H. H. Joni, and S. Adnan, Effect of Plastic Optical Fibers on properties of translucent concrete boards, in Proceedings of The First International Conference on Engineering Sciences' Applications, ICESA, 2014.

[33] S. L. Pagliolico, V. R. L. Verso, A. Torta, M. Giraud, F. Canonico, and L. Ligi, A preliminary study on light transmittance properties of translucent concrete panels with coarse waste glass inclusions, Energy Procedia, vol. 78, pp. 1811-1816, 2015. doi: 10.1016/j.egypro.2015.11.317

[34] J. Shen and Z. J. J. o. E. E. Zhou, Performance and Energy Savings of Resin Translucent Concrete Products, vol. 146, no. 3, p. 04020007, 2020. doi.org/10.1061/(ASCE)EY.1943 $-7897.0000652$

[35] A. Ahuja, K. M. Mosalam, and T. I. Zohdi, Computational modeling of translucent concrete panels, Journal of Architectural Engineering, vol. 21, no. 2, p. B4014008, 2014. doi: 10.1061/(ASCE)AE.1943-5568.0000167.

[36] A. Ahuja and K. M. Mosalam, Evaluating energy consumption saving from translucent concrete building envelope, Energy and Buildings, vol. 153, pp. 448-460, 2017. doi: 10.1016/j.enbuild.2017.06.062.

[37] R. d. S. S. Amorim, Análise teórica e experimental da condutividade térmica e transmitância em blocos de concreto translúcido, M.Sc. M.Sc., Engenharia Civildo UniCEUB, Centro Universitário deBrasíliaOrientador, 2018.

[38] S. Juan and Z. Zhi, Preparation and Study of Resin Translucent Concrete Products, Advances in Civil Engineering, vol. 2019, 2019. doi: 10.1155/7074

[39] X. Su, L. Zhang, Z. Liu, Y. Luo, J. Lian, and P. Liang, Daylighting performance simulation and analysis of translucent concrete building envelopes, Renewable Energy, 2020. doi.org/10.1016/j.renene.2020.03.041 